\title{
A qualitative assessment of an online support community for ovarian cancer patients
}

\author{
This article was published in the following Dove Press journal: \\ Patient Related Outcome Measures \\ 3 October 2012 \\ Number of times this article has been viewed
}

\section{Preetinder Singh Gill Billy Whisnant}

College of Technology, Eastern Michigan University, Ypsilanti, MI, USA
Correspondence: Preetinder S Gill College of Technology, Eastern Michigan University, I59 Sill Hall Ypsilanti, MI 48197, USA

Tel +l 7344872338

Fax +I 7344870843

Email pgill I@emich.edu
Background: A diagnosis of ovarian cancer can have detrimental effects on afflicted patients and their families. Therefore, it is important to understand the role online communities play in improving the quality of life of those affected by the disease.

Purpose: The aim of this research study is to illustrate the role that online communities play in helping patients and their families to deal with ovarian cancer.

Methods: Data were collected from an online ovarian cancer forum hosted by MedHelp.org in the form of transcripts of participant discussions. No identifying information about participants was collected. Grounded theory, a qualitative research method, was employed to develop a theory by analyzing the data. The aim of the analysis was to explore the role this forum played in ovarian cancer disease management.

Results: Data analysis helped to determine participant roles and behaviors. The results suggested that an information seeker-information provider communication process existed among users of the forum observed. Participants in the online forum shared both technical and emotional knowledge and experience in order to achieve self-management of the disease while building trust and support.

Conclusions: This study concluded that online discussion forums can play a crucial and indispensable role in dealing with diseases such as ovarian cancer, for which limited treatment options exist. Health educators can leverage online discussion forums to promote lifestyle choices and disseminate information about treatment and testing, while getting active feedback from the audience.

Keywords: online discussion forums, community, disease management, self-management, trust, support

\section{Introduction}

Recent projections from the American Cancer Society state that in the United States 22,280 women will be diagnosed with ovarian cancer and 15,500 women will die from the disease in 2012. ${ }^{1}$ In the lifetime of a woman, her risk of developing invasive ovarian cancer is $1.41 \%^{2}$ and the risk of dying from invasive ovarian cancer is $1.05 \%$, with an overall 5 -year survival rate of $46 \%$. Specific rates of survival depend on the stage the cancer is in when a physician makes the diagnosis. ${ }^{2}$

In 2009, a study of stage IIIC epithelial ovarian cancer patients found that the mean cost of treatment was US\$211,940 over the course of the treatment. ${ }^{3}$ The survival rate was found to be $30 \%$, and only $9 \%$ of the patients in the study were ovarian cancerfree after 5 years. ${ }^{3}$ It was also found that the cost of treatment ranged from $\$ 85,760$ to $\$ 555,280 .{ }^{3}$ Furthermore, the average cost of treatment of epithelial ovarian cancer has increased fourfold over a period of 20 years. ${ }^{4}$ 
Decruyenaere et $\mathrm{al}^{5}$ and Lancastle et $\mathrm{al}^{6}$ highlighted that ovarian cancer patients undergo emotional distress and experience erosion in the quality of their lives. Northouse et $\mathrm{al}^{7}$ noted that families and loved ones of ovarian cancer patients also undergo psychological and physiological issues. Therefore, it is imperative to develop novel solutions to care for people directly or indirectly affected by ovarian cancer.

The risk of developing ovarian cancer increases with age. ${ }^{8-10}$ The rising age of the overall population underscores the need to provide efficient and effective support to women afflicted by the disease. Considering the urgency for care and the costs associated with this disease, it is interesting to note that Korstjens et al found that group-based self-management played a positive role in improving the quality of life of cancer survivors. ${ }^{11}$

\section{Online discussion forums}

Online discussion forums are websites that allow users to make contributions to discussions. The discussions in these forums focus on a large array of topics. A Google search performed on May 10, 2012 for the string "online discussion forums" returned over 40 million results. Wells and Sevilla maintained that an online discussion forum is where questions can be posted for informal answers and discussion. ${ }^{12}$ Online discussion forums can become a vibrant source of ideas and sharing. Forums can be created using sophisticated software, often available for free. ${ }^{13}$ Forum sites are usually run and controlled by administrators and/or moderators. The administrators and/or moderators can check all contributions to the forums, and they can ban members or create areas for private/nonpublic areas. ${ }^{13}$ Furthermore, Shaul asserted that online forums could serve as a socially constructive learning tool. ${ }^{14} \mathrm{He}$ classified online forums as into three categories: social/opinion forums, general discussion forums, and topic-specific forums. Besides these three categories, Gordon also added company/product-specific forums to the list of categories. ${ }^{15}$ Beuchot and Bullen ${ }^{16}$ and Chalkitia and Sigala ${ }^{17}$ maintained that online forums facilitate in collective knowledge-building and knowledge management.

Multiple studies have been conducted on the use of health care-related online discussion forums as a method of providing patient support. Adler and Adler identified that online discussion forums can go beyond the boundaries of simple information discovery and can be a source of support for individuals. ${ }^{18}$ As an example, women using an online discussion forum for menopausal support were found to be using the forum for redefining self, laughing at suffering, differences within sameness, and talking to the wall. ${ }^{19}$ A study of a self-harm support forum found that forums develop their own hierarchies.$^{20} \mathrm{~A}$ forum with less moderation will take on a flatter hierarchy, where users depend on one another to form behavioral norms, and when individuals on a forum post in a way that is counter to the culture of the forum, other users will correct the behavior. ${ }^{20}$ Work concerning the use of the Internet in the treatment of social phobias has determined that significant improvements can be made whether or not the support is provided by a professional therapist. ${ }^{21}$

A review of the literature conducted by Barak et al determined that the use of online support groups is effective as a source of support for an individual with a specific condition. ${ }^{22}$ However, the support group can have limited to no influence on the treatment of the condition. The use of computermediated communication can also help to overcome the many challenges presented by specific medical conditions. ${ }^{22}$ The review showed that the interactions of community members in an online support forum built around ovarian cancer have not been adequately studied. Therefore, this study was designed to observe the interactions of the users of an ovarian cancer online support forum as a way to develop theories concerning the use of online support communities.

\section{Research questions}

The purpose of this study was to gain an insight of the online forums that have been built around ovarian cancer. Research questions addressed by this study are:

1. What is the nature of the structure of this community?

2. What roles do different users play?

3. For what reasons do individuals participate in these forums?

4. What is the process that underlies communication in this community?

\section{Methodology}

This study focused on the behaviors and interactions of individuals in an online ovarian cancer community forum with an objective to develop a comprehensive understanding of participant behaviors and interactions. A qualitative research methodology called grounded theory ${ }^{23}$ was used to develop substantive theories that can explain this phenomena.

\section{Subjects}

The population associated with this study included all participants on online ovarian cancer community support forums. The sample of the population included subjects who posted on MedHelp International's ovarian cancer health forum which can be accessed via the following link: http://www.medhelp.org/forums/Ovarian-Cancer/show/94. 
The stated objective of MedHelp.org is to provide medical information and support to its users. This is achieved by two types of forums hosted on the website. The professional-led forums involve medical professionals answering queries from website users. These are called doctor forums. The second set of forums is called health forums. These forums provide communal support. Any website user can post questions or answers on the health forums. As of Aug 27, 2012, MedHelp.org hosted a total of 271 health forums associated with various health conditions. The ovarian cancer health forum is one of these 271 forums. Identifying information of any of the subjects of this study was not collected or included in the analysis. Furthermore, all users of MedHelp. org, including the subjects of this study, used nonidentifiable pseudonyms. The subjects of this study were not delineated or excluded from analysis for any reason. All communications in the online community were studied without regard to posters' histories with ovarian cancer or the nature of their professional experience. This approach ensured that communications were not tainted by the potential desire of a user to behave differently under evaluation. Approval to observe the communications among participants in the online community forum was granted by the management of MedHelp International.

A comparison performed on Alexa, an Internet trafficreporting website, on May 17, 2012 showed that MedHelp.org had a substantial amount of traffic. The amount of traffic to the ovarian cancer forum could not be determined. A comparison of MedHelp.org and its competitors in terms of their traffic rank reported by Alexa is shown in Table 1. In July 2012, MedHelp. org received 3.7 million visits. MedHelp International's website claims that MedHelp.org has over 12 million users. Furthermore, among its competitors, MedHelp.org is the only website that primarily focuses on user-driven community forums. The combination of the relatively high amount of web traffic and focus on discussion forums led the researchers to choose this forum for this study.

\section{Data collection}

Data were collected in the form of transcripts of all posts made on public discussion threads included in MedHelp

Table I Comparison of various online health discussion forum websites

\begin{tabular}{ll}
\hline Website name & Traffic rank \\
\hline medhelp.org & 4152 \\
webmd.com & 518 \\
emedicinehealth.com & 4046 \\
healthcentral.com & 6038 \\
ehealthforum.com & 6236 \\
\hline
\end{tabular}

International's online ovarian cancer forum before 11:59 pm EST on May 15, 2012. Posts made in these threads after 11:59 pm on May 15, 2012 were not used in this study. The posts included in this study were made by 93 unique users. Data collection for this study was continued until a theoretical saturation was achieved. Theoretical saturation for the grounded-theory approach is associated with continuation of sampling and data collection until no new conceptual insights are generated. ${ }^{24,25}$

In order to determine theoretical saturation, data were observed by researchers ${ }^{26}$ as conversations in threads grew and evolved. The researchers conducted note-taking and classification of data as a way to determine patterns. Theoretical saturation was indicated by repetition in observed conceptual categories associated with the content of the posts. ${ }^{26}$ The entire data set did not have to be reviewed to reach theoretical saturation. Theoretical saturation was reached after reviewing 118 discussion threads/topics.

\section{Qualitative data analysis}

Qualitative analysis was performed to answer the four research questions with an aim of developing theories grounded in data. The grounded-theory approach, as proposed by Corbin and Strauss, was used for data analysis. ${ }^{26}$ It must be noted that the processes of data collection and analysis are interrelated in such an approach. ${ }^{26}$ The analysis begins as soon as data collection is initiated. ${ }^{24}$ The four steps associated with the grounded-theory approach are described below:

1. Open coding: This step involved categorizing the data based on conceptual similarity to reduce it to a set of themes that describe the phenomenon under investigation. ${ }^{27}$ Words, phrases, or events that appeared to be similar were clubbed under the same category. ${ }^{28}$ Pursuant to such categorization, the data were analyzed for specific attributes that constituted each category.

2. Axial coding: In this step, interrelations were established among categories generated through open coding. Additional details were generated for each category based on: (1) conditions that gave rise to it, (2) context in which it was embedded, (3) strategies that people used to manage and execute it, and (4) effects of these strategies. ${ }^{27}$

3. Selective coding: A story line explaining the phenomena observed on the discussion forum was formed in this step of data analysis. A narrative was developed to approximate the reality it represents..$^{27}$ This narrative was based on the categories generated in open coding and interrelations established in axial coding. 
4. Development of a theory: Theories based on selective coding were generated to depict the evolving nature of the phenomenon being studied. The theories also described the conditions and actions that progressively led to the typical sequence of events. ${ }^{26}$

\section{Results}

The structure of community in an ovarian cancer online community

One of the first patterns that emerged in observation of the discussions between users in the forum studied was the structure of communication. Threads were created when there was something that was desired from others in the community. Users asked fellow community members questions as a way to spur on conversation. Users did not commonly begin a thread to share information or to encourage relatedness amongst other community members. In the period studied, there appeared to be only a few examples of users beginning threads not looking for something from others, and these threads did not receive participation from other users.

Additionally, thread size appeared rather bimodal, in that a thread either had zero to two posts on it or had multiple posts of seven to ten quite commonly. Threads where a user was requesting technical information were usually answered by users who had high post counts. A high post count means that the user has participated in many discussions. Concerning frequent posters, their participation in a thread where technical information was requested would usually be the concluding post in the thread. Posts made by these users regarding their education and professional background suggested a varying degree of experience in medicine from none to being a professional practitioner (Figure 1). It seems plausible that there was an assumption of authority among posters regarding users who frequently participated.

A different observation was made for threads regarding emotional support issues. Participants who frequently posted in these threads participated in a way that offered empathy and catharsis for both themselves and the person who started the thread. The original poster of the thread framed the thread as a question to be answered. Other members of the community commonly participated with well wishes or sharing their own stories and experiences. Threads concerning a technical or educational issue received a simple clinical answer. However, threads regarding support became an opportunity for soul cleansing and emotional discussion (Table 2).

\section{Roles of users in an ovarian cancer online community}

The roles of users in the forum emerged from the qualitative analysis. As discussed previously, threads would commonly begin with a question or some sort of request for explanation regarding treatment, care, or living with the disease or a loved one with the disease. People who began threads were classified as information seekers. Participants in threads then responded with either information, an anecdote, or emotional support of some kind. These people were information providers. The role assumed by those who participated in threads rarely deviated from that of being an information provider (Table 3 ). Information providers also appeared to get something out of participation in threads, as it allowed them to tell their story or be a part of the community. They did not expressly seek anything from other users.

Specific subgroups/categories were observed among information providers. As discussed previously, there were a few posters who had significantly higher post counts than other users. These posters are referred to as regulars, as they are people who regularly participated in the discussion. Nonregular posters did not frequently participate as information providers. Regulars participated in both technical and support threads. Their participation in technical threads commonly resulted in the end of the discussion. However, their participation in support threads did not end the discussion. Regulars also cleansed the forum if they sensed that someone gave biased information. As an example, in one specific event, a regular noted that a poster was trying to push a product as a salesperson. This person ceased posting after being exposed.

\section{Reasons for participation in an ovarian cancer online community}

Detailed assessment of roles that individuals played in the online community and analysis of their interactions demonstrated that specific features are associated with this community. Both information seekers (Figure 1) and information providers (Figure 2) shared that they sought or delivered self-management assistance, support, and trust (Figure 3). Self-management involves patient education and practice of care by the patient. The difference between traditional patient education and self-management education is that while traditional patient education offers information and technical skills, self-management education also teaches problem-solving skills. ${ }^{29}$ Technical information requested by information seekers could be categorized into two segments: trust and self-management. 


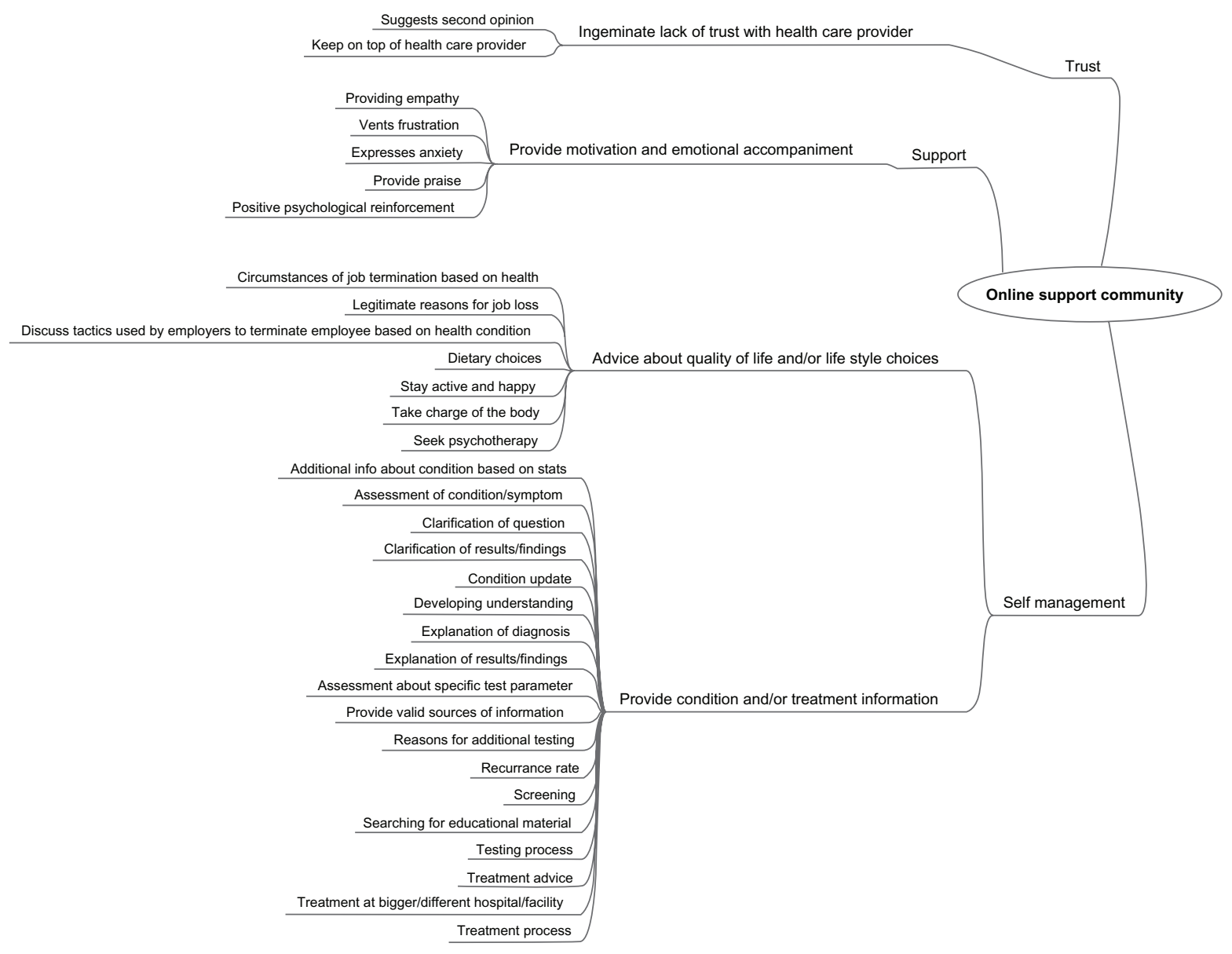

Figure I Qualitative data analysis for information-provider role.

Patients concerned about such things as their doctors "doing the sit and wait" or waiting to see the progression of the disease before moving forward with treatment were commonplace. These concerns in turn highlighted trust issues. Further, patients and their loved ones asked about what test results meant as a way to determine whether their health-care providers were being honest with them. It was found that the online forum was often used by patients when trust in a physician after a visit was low or when an imminent or recent visit increased their anxiety. This is consistent with findings of other research studies. ${ }^{30}$

Self-management was a very frequent occurrence in this forum. Information seekers commonly asked questions regarding quality of life and lifestyle management, such as diet and activities as well as self-care during and after treatment, as well as the effects of treatment on their lifestyle. Information providers responded with brief clinical answers. Information providers would provide personal and diseaserelated information as a way to ensure the most accurate answer. If enough information was not given with a query, the thread was either ignored or the information seeker was asked additional/follow-up questions by an information provider. Self-management threads were short in nature. They usually ended with the participation of a regular giving advice. It was a somewhat rare occurrence to have two or more regulars posting in the same self-management thread.

Table 2 Structure of support types in an ovarian cancer support forum

\begin{tabular}{|c|c|c|c|c|}
\hline $\begin{array}{l}\text { Type of } \\
\text { support }\end{array}$ & $\begin{array}{l}\text { Typical \# } \\
\text { of replies }\end{array}$ & $\begin{array}{l}\text { Nature } \\
\text { of responses }\end{array}$ & $\begin{array}{l}\text { Reasons } \\
\text { for response }\end{array}$ & $\begin{array}{l}\text { Original poster } \\
\text { participation after first post }\end{array}$ \\
\hline Technical & $0-2$ & Clinical & $\begin{array}{l}\text { Deliver requested } \\
\text { information }\end{array}$ & $\begin{array}{l}\text { Clarification; further information; } \\
\text { give thanks }\end{array}$ \\
\hline Emotional & $5-10$ & Supportive & $\begin{array}{l}\text { Emotional support; } \\
\text { empathy; catharsis }\end{array}$ & $\begin{array}{l}\text { Empathy for other posters; } \\
\text { catharsis; give thanks }\end{array}$ \\
\hline
\end{tabular}


Table 3 Roles of posters in an ovarian cancer support forum

\begin{tabular}{lll}
\hline $\begin{array}{l}\text { Role of } \\
\text { poster }\end{array}$ & Subgroups & Reasons for participation \\
\hline $\begin{array}{lll}\text { Information } \\
\text { seeker }\end{array}$ & Common poster & $\begin{array}{l}\text { Looking for advice; solutions or } \\
\text { information regarding treatment; } \\
\text { care and emotional issues }\end{array}$ \\
$\begin{array}{lll}\text { Information } \\
\text { provider }\end{array}$ & $\begin{array}{l}\text { Nonregular poster; } \\
\text { regular poster }\end{array}$ & $\begin{array}{l}\text { Deliver information; participate in } \\
\text { community; outlet for emotions }\end{array}$ \\
\hline
\end{tabular}

It seemed that this was a showing of respect among regulars for their work in the community.

Support was quite different from the technical nature of threads where trust and self-management responses were sought. Support elicited emotional responses from information providers. The distinction between information seeker and information provider seemed to blur in a few of these threads. Common occurrences in these threads were that they began with an information seeker venting frustration while looking for empathy from the community. Responses by community members included recollections of personal experiences, expressions of anxiety or empathy, or praise or reinforcement for the information seeker. In some instances, the information seeker would rejoin the thread and offer the same things to the information provider.

\section{Process of communication in an ovarian cancer online community}

While information seekers began a thread based on trust, support, or self-management, the basis for communication in this community was the sharing of technical or emotional knowledge or experience. Technical knowledge and experience represented self-management. Emotional knowledge and experience represented support. Trust appeared to be somewhere in the middle. Technical knowledge and experience appeared not to be as salient a topic as emotional knowledge and experience. However, there appeared to be a desire to share technical knowledge and experience among a limited number of regular information providers. In a selfmanagement thread, there were a few regulars who frequently participated. These regular information providers often used the post also as a way to share emotional knowledge and experience. In a thread where trust was the basis for discussion, a similar phenomenon was observed. However, informationprovider responses were more emotional knowledge-based and experience-centric than in self-management threads. Threads where an information seeker was looking for support commonly received emotional knowledge and experience in response from information providers (Figure 4).

\section{Descriptive data analysis}

Descriptive statistical analysis showed that there was consistency in frequencies among information seekers and information providers concerning trust. Trust was the least frequently discussed topic on the forum. Information providers discussed trust in $7.2 \%$ of their posts and information seekers discussed it in $7.6 \%$ of their posts. Information providers discussed self-management $46 \%$ of the time. Information seekers discussed self-management $70.9 \%$ of the time. A large difference existed between informationprovider participation and information-seeker participation

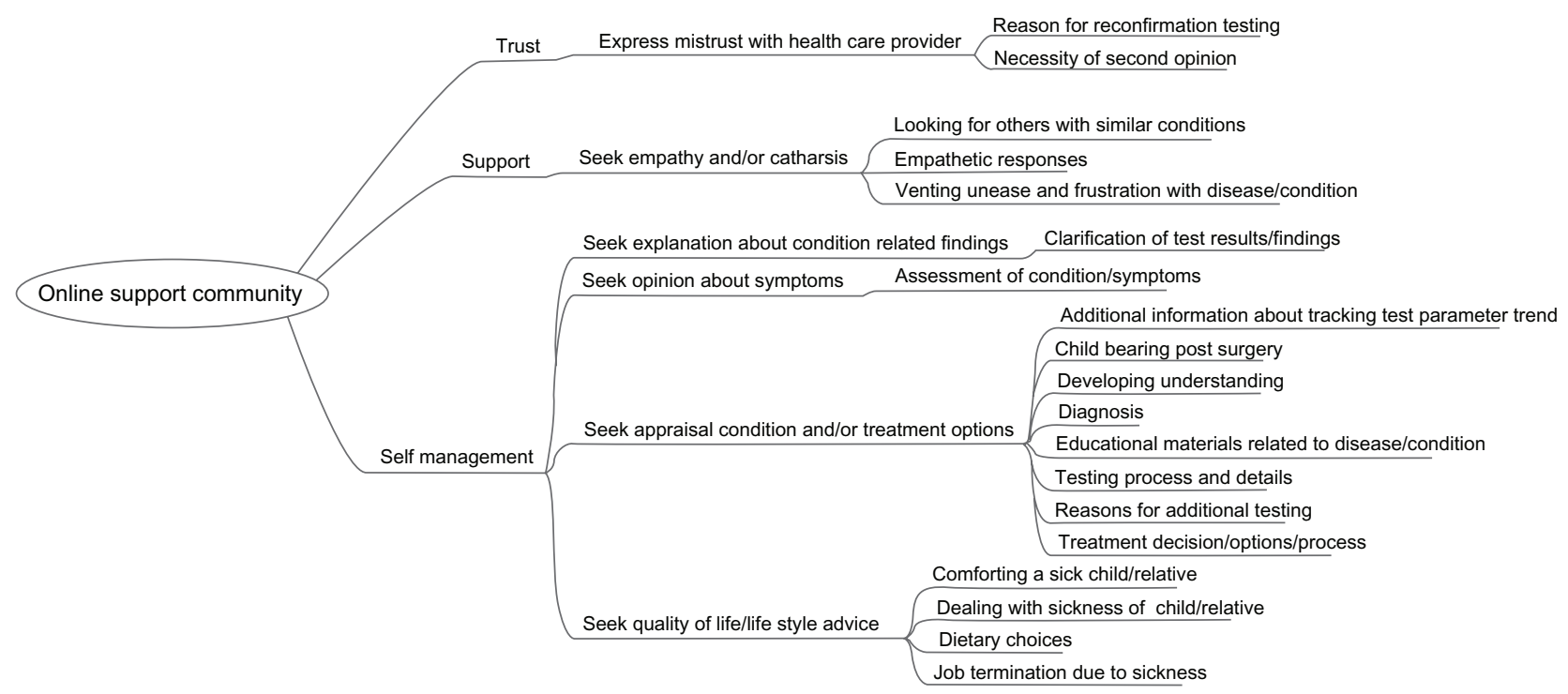

Figure 2 Qualitative data analysis for information-seeker role. 


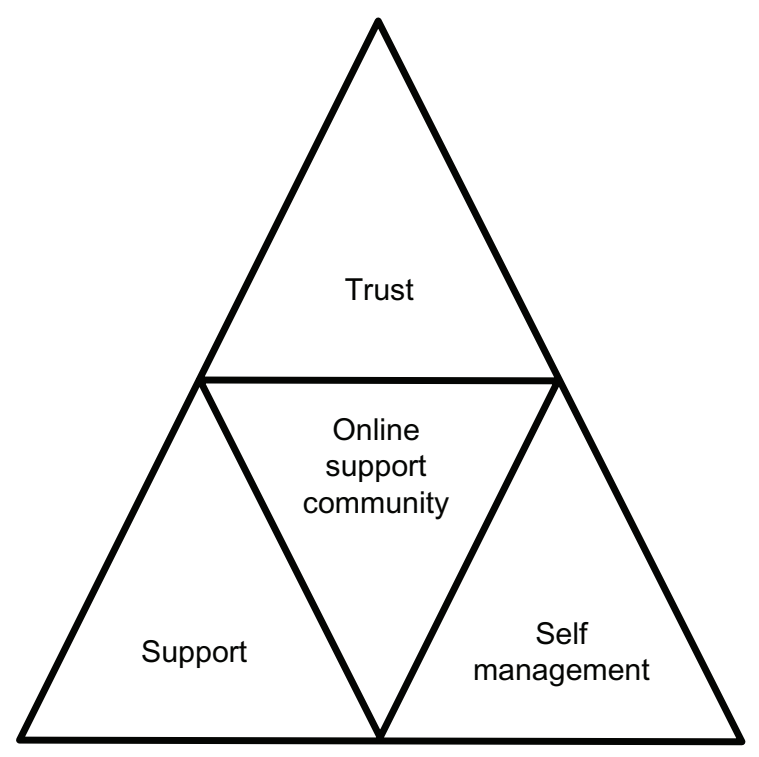

Figure 3 Model of participation in the ovarian cancer support forum.

in support-related discussions. Only 17 posts were made by information seekers on the support topic, but 65 posts were made by information providers on this topic. This suggested that information seekers and information providers might have different reasons for participating in this forum. It was found that information seekers participated prominently in self-management topics, whereas information providers participated prominently in support and self-management topics. Detailed descriptive data analysis is presented in Table 4.

\section{Discussion}

The findings of this study suggested that while some users may be passive in the community others may be quite active.

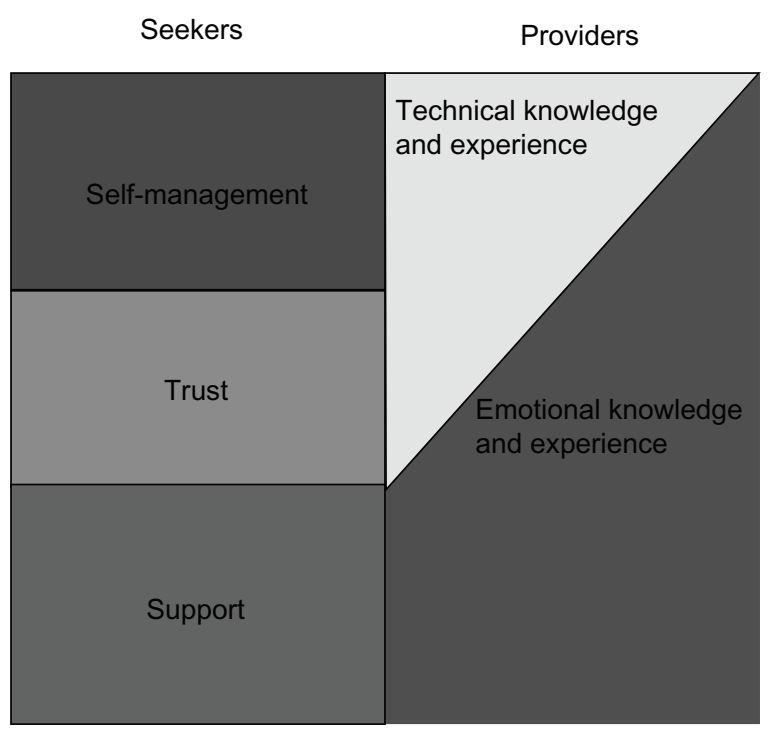

Figure 4 Process of communication in the ovarian cancer support forum.
Table 4 Descriptive data analysis of posts made under specific topics

\begin{tabular}{lll}
\hline & $\begin{array}{l}\text { Frequency } \\
\text { (number) }\end{array}$ & $\begin{array}{l}\text { Frequency } \\
\text { (percent) }\end{array}$ \\
\hline Information provider & & \\
Trust & 10 & 7.2 \\
Support & 65 & 46.8 \\
Self-management & 64 & 46 \\
Total & 139 & 100 \\
Information seeker & & \\
Trust & 6 & 7.6 \\
Support & 17 & 21.5 \\
Self-management & 56 & 70.9 \\
Total & 79 & 100 \\
\hline
\end{tabular}

There were three drivers that brought individuals to participate in the online forum studied: self-management, trust, and support (Figure 3). As the basis of this forum is to provide support, it is not surprising that support and trust are two reasons for participation. Desire to seek self-management support and technical knowledge from other users is particularly interesting, since the users did not seem to know each other in person. This finding suggested that there is a value placed on the experience of laypeople. Mistrust in the word or actions of the physician arose as a significant driver for becoming an information seeker, further bolstered by the idea that the layperson is valued by those in this community. A plausible explanation for this observation could be that information seekers considered information providers as neutral parties without any ulterior motives.

Future studies may wish to examine trust, self-management, and support as outcome variables among information seekers and information providers, as moderated by their relationship with this disease. Future studies could also verify the results of this study by analyzing data from other online sources. Triangulation ${ }^{31}$ based on findings from other studies can help to generalize the results and findings of this study. Other studies may determine the influence of introducing a professional into an online support community. Additionally, further studies could employ quantitative methods to increase the validity of the findings in this study. These studies could quantify the role of information technology in building more cohesive communities. Long-term qualitative work could determine the transformational process of a poster as the poster moves from being an information seeker to being an information provider.

\section{Conclusion}

As the findings of this study suggest, the online ovarian cancer community forum was a place to seek and provide 
technical and emotional support, education, and experience. While information seekers often came to the forum as passive users, there was a core handful of active information providers who commonly participated and shared their knowledge and experience. Information seekers looked for answers regarding self-management, trust, and emotional support. The information providers were commonly looking for something as well: an opportunity to be part of a community, provide empathy, and search for catharsis.

\section{Acknowledgments}

We would like to acknowledge MedHelp International for providing access to the data associated with the ovarian cancer online discussion forum. We would like to especially thank Ms Cindy Thompson, cofounder and vice president of MedHelp International for her support. Also, we greatly appreciate the invaluable advice of Dr John Dugger and Dr Joan Cowdery of Eastern Michigan University.

\section{Disclosure}

The authors have produced this paper as impartial and nonbiased investigators. There is no conflict of interest on behalf of either author of this paper.

\section{References}

1. American Cancer Society. Ovarian cancer. 2011. Available from: http:// www.cancer.org/acs/groups/cid/documents/webcontent/003130-pdf.pdf. Accessed May 3, 2012.

2. Ovarian Cancer National Alliance. Ovarian cancer statistics. 2012. Available from: http://www.ovariancancer.org/about-ovarian-cancer/ statistics. Accessed May 3, 2012.

3. Cooper AL, Nelson DF, Doran S, Ueland FR, et al. Long-term survival and cost of treatment in patients with stage IIIC epithelial ovarian cancer. Curr Womens Health Rev. 2009;5:44-50.

4. Etzioni R, Urban N, Baker M. Estimating the costs attributable to a disease with application to ovarian cancer. J Clin Epidemiol. 1996;49:95-103.

5. Decruyenaere M, Evers-Kiebooms G, Welkenhuysen M, Denayer L, Claes E. Cognitive representations of breast cancer, emotional distress and preventive health behaviour: a theoretical perspective. Psychooncology. 2000;9:528-536.

6. Lancastle D, Brain K, Phelps C. Illness representations and distress in women undergoing screening for familial ovarian cancer. Psychol Health. 2011;26:1659-1677.

7. Northouse L, Williams A, Given B, McCorkle R. Psychosocial care for family caregivers of patients with cancer. J Clin Oncol. 2012;30: $1227-1234$.
8. Hartge P, Wittlemore A, Intyre J, McGowan L, Cramer D. Rates and risks of ovarian cancer in subgroups of white women in the United States. The Collaborative Ovarian Cancer Group. Obstet Gynecol. 1994;84:760-764.

9. Yancik R. Ovarian cancer: age contrasts in incidence, histology, disease stage at diagnosis and mortality. Cancer. 1993;71:517-523.

10. Lynch H, Watson P, Bewtra C, et al. Hereditary ovarian cancer. Heterogeneity in age at diagnosis. Cancer. 1991;67:1460-1466.

11. Korstjens I, May AM, van Weert E, Mesters I, et al. Quality of life after self-management cancer rehabilitation: a randomized controlled trial comparing physical and cognitive-behavioral training versus physical training. Psychosom Med. 2008;70:422-429.

12. Wells TD, Sevilla C. Maximizing the Enterprise Information Assets. Boca Raton: CRC Press; 2003.

13. Dye B. Online forums. Micromath. 2005;21:34-37.

14. Shaul M. Assessing online discussion forum participation. Int J Inf Commun Technol Educ. 2007;3:39-46.

15. Gordon RS. Online discussion forums. Link-Up. 2000;12:12.

16. Beuchot A, Bullen M. Interaction and interpersonality in online discussion forums. Distance Educ. 2005;26:67-87.

17. Chalkitia K, Sigala M. Information sharing and knowledge creation in online forums: the case of the Greek online forum 'DIALOGOI'. Curr Issues Tourism. 2008;11:381-406.

18. Adler PA, Adler P. The cyber worlds of self-injurers: deviant communities, relationships and selves. Symbol Interact. 2008;31:33-56.

19. Im E, Yi L, Dormire S, Chee W. Menopausal symptom experience: an online forum study. J Adv Nurs. 2008;62:541-550.

20. Smithson J, Sharkey S, Hewis E, et al. Membership and boundary maintenance on an online self-harm forum. Qual Health Res. 2011;21: $1567-1575$.

21. Berger T, Caspar F, Richardson R, Kneubühler B, Sutter D, Andersson G. Internet-based treatment of social phobia: a randomized controlled trial comparing unguided with two types of guided self-help. Behav Res Ther. 2011;49:158-169.

22. Barak A, Boniel-Nissim M, Suler J. Fostering empowerment in online support groups. Comput Human Behav. 2008;24:1867-1883.

23. Merriam SB. Qualitative Research: A Guide to Design and Implementation. San Francisco: Jossey-Bass; 2009.

24. Safman RM, Sobel J. Qualitative sample extensiveness in health education research. Health Educ Behav. 2004;31:9-21.

25. Bloor M. Keywords in Qualitative Methods: A Vocabulary of Research Concepts. London: Sage; 2006.

26. Corbin J, Strauss A. Grounded theory research: procedures, canons and evaluative criteria. Z Soziol. 1990;19:418-427.

27. Leedy PD, Ormrod JE. Practical Research: Planning and Design. Upper Saddle River: Pearson/Merrill Prentice Hall; 2010.

28. Hoepfl MC. Choosing qualitative research: a primer for technology education researchers. J Technol Educ. 1997;9:47-63.

29. Bodenheimer TL, Lorig K, Holman H, Grumbach K. Patient selfmanagement of chronic disease in primary care. JAMA. 2005;288: 2469-2475.

30. Bell R, Hu X, Orrange SE, Kravitz RL. Lingering questions and doubts: online information-seeking of support forum members following their medical visits. Patient Educ Couns. 2011;85:525-528.

31. Taylor SJ, Bogdan R. Introduction to Qualitative Research Methods. New York: John Wiley \& Sons; 1998.
Patient Related Outcome Measures

\section{Publish your work in this journal}

Patient Related Outcome Measures is an international, peer-reviewed, open access journal focusing on treatment outcomes specifically relevant to patients. All aspects of patient care are addressed within the journal and practitioners from all disciplines are invited to submit their work as well as healthcare researchers and patient support groups.

\section{Dovepress}

The manuscript management system is completely online and includes a very quick and fair peer-review system. Visit http://www.dovepress. $\mathrm{com} /$ testimonials.php to read real quotes from published authors. 